\title{
Effect of aging on calcium signaling in C57Bl6J mouse cerebral arteries
}

\author{
Carole Georgeon-Chartier • Céline Menguy • \\ Anne Prévot • Jean-Luc Morel
}

\begin{abstract}
In cerebral arteries, alterations of vascular reactivity have been observed but not well molecularly characterized. Therefore, we have hypothesized that cerebrovascular reactivity could be modified by aging via a modification of $\mathrm{Ca}^{2+}$ signaling in smooth muscle cells. $\mathrm{Ca}^{2+}$ signals and gene expression implicated in contraction have been measured in posterior and middle cerebral arteries from young (23 months) and old (20-22 months) C57Bl6/J mice. Aging
\end{abstract}

C. Georgeon-Chartier $\cdot$ J.-L. Morel $(\bowtie)$

Institut des Maladies Neurodégénératives, UMR 5293,

Universite Bordeaux,

33076 Bordeaux Cedex, France

e-mail: jean-luc.morel@u-bordeaux2.fr

C. Georgeon-Chartier

e-mail: carole.georgeon@u-bordeaux2.fr

C. Georgeon-Chartier · J.-L. Morel

Institut des Maladies Neurodégénératives, UMR 5293, CNRS,

33076 Bordeaux Cedex, France

C. Menguy

Génétique des Maladies Vasculaires, UMR-S 740,

Universite Paris Diderot-Paris 7,

75010 Paris, France

e-mail: celine.menguy@univ-paris-diderot.fr

C. Menguy

Génétique des Maladies Vasculaires, UMR-S 740, INSERM,

75010 Paris, France

\section{A. Prévot}

Department of Medicine/Physiology, Universite de Fribourg,

CH-1700 Fribourg, Switzerland

e-mail: prevotanne@hotmail.com induced a decrease of $\mathrm{KCl}$ - and caffeine-induced contraction as well as a decrease of the amplitudes and an increase of the durations of $\mathrm{KCl}-$ and caffeine-induced $\mathrm{Ca}^{2+}$ signals. These results could be linked with the decrease of gene expression coding for Cav1.2, RyR2, SERCA2, PLB, STIM1, TRIC-B, and the increase of FKBP12.6 and TPCN1 gene expression. Finally, aging induced a modification of InsP3 subtype expression pattern responsible for a modification of the InsP3 affinity to activate $\mathrm{Ca}^{2+}$ signals. These results show that aging induces a decrease of contractility correlated with modifications of the expression of genes encoding $\mathrm{Ca}^{2+}$ signaling toolkit. Globally, the amplitude of $\mathrm{Ca}^{2+}$ signals was decreased, whereas their duration was increased by a defection of $\mathrm{Ca}^{2+}$ store refilling.

Keywords Aging $\cdot$ Cerebral artery $\cdot \mathrm{Ca}^{2+}$-induced $\mathrm{Ca}^{2+}$ release $\cdot \mathrm{Ca}^{2+}$ channels

\section{Introduction}

Aging has a significant effect on vascular functions, especially the decrease of compliance in large arteries and the decrease of reactivity in small arteries [37]. Aging induces direct structural and functional modifications of smooth muscle cells (SMC) that could affect contraction relaxation, cellular phenotype, and proliferation/regeneration. Previously well demonstrated, these cellular processes involve specific $\mathrm{Ca}^{2+}$ signals [2-4]. In addition, vascular SMC (VSMC) help to ensure the regulation of myogenic tone and blood pressure. The contraction/relaxation balance is regulated in part by $\mathrm{Ca}^{2+}$ signals and activation of $\mathrm{Ca}^{2+}$-activated $\mathrm{K}^{+}$channels.

In VSMC, the $\mathrm{Ca}^{2+}$ signals are complex [3] as summarized in Fig. S1: depolarisation induces the activation of L-type currents mediated by voltage-gated $\mathrm{Ca}^{2+}$ channels (containing CaV1.2 subunits). The $\mathrm{Ca}^{2+}$ entry is then relayed and amplified by the release of $\mathrm{Ca}^{2+}$ stored in sarcoplasmic reticulum (SR) via the 
$\mathrm{Ca}^{2+}$-induced $\mathrm{Ca}^{2+}$ release mechanism (CICR) due to activation of ryanodine receptors (RyR). Hormones and neuromediators activate transduction pathways to produce second messengers responsible for the release of stored $\mathrm{Ca}^{2+}$ by three distinct mechanisms: (1) inositol 1,4,5-trisphophate (InsP3) via activation of InsP3 receptors (InsP3R); (2) cyclic ADP ribose (cADPR) via the decoupling between RyR2 and calstabin-2 (or FKBP12.6) known to stabilize RyR2 in closed conformation [20]; and (3) nicotinic acid adenine dinucleotide phosphate (NAADP) via activation of RyR and/or two pore channels encoded by TPCN genes [9]. The return to the basal $\mathrm{Ca}^{2+}$ concentration after an agonist- or depolarisation-activated $\mathrm{Ca}^{2+}$ response results from (1) $\mathrm{Ca}^{2+}$ extrusion by plasma membrane $\mathrm{Ca}^{2+}$-ATPases (PMCA) and $\mathrm{Ca}^{2+}$ store refilling via sarco/endoplasmic reticulum $\mathrm{Ca}^{2+}$-ATPases (SERCA); (2) store-operated $\mathrm{Ca}^{2+}$ entry (SOCE) supported by the partnership between stromal interacting molecule (STIM) and Orai participated in the regeneration of the $\mathrm{SR} \mathrm{Ca}^{2+}$ store $[19,31]$; and (3) very recently, trimeric intracellular channels (TRIC) were described to contribute to blood pressure maintenance by the regulation of the storedependent $\mathrm{Ca}^{2+}$ release [63], while SOCE-associated regulatory factor (SARAF) controls the store-operated $\mathrm{Ca}^{2+}$ entry to prevent excess $\mathrm{Ca}^{2+}$ refilling [45]. The simultaneous activity of these proteins (known altogether as the " $\mathrm{Ca}^{2+}$ signaling toolkit") participates to the intracellular signals necessary for cellular functions, particularly vascular contraction.

Aging is also characterized by the modulation of gene expression [46]. In the heart, the study of gene expression by DNA arrays showed that aging affected $10 \%$ of expressed genes, indicating the complexity of aging effects on gene expression $[29,61]$. These results provided pathways to describe and understand aging effects on physiology. For example, in pyramidal neurons, it has been demonstrated that aging induces changes in $\mathrm{Ca}^{2+}$ signaling $[22,56]$. In aged animals, increases of L-type $\mathrm{Ca}^{2+}$ current and channel density were measured in aged hippocampal neurons, resulting in increased slow after hyperpolarization spikes [55, 56]. Consequently, a decrease of long-term potentiation was observed which could explain at least partly the aging-dependent cognitive impairments. Indeed, the use of nimoldipine, an inhibitor of L-type $\mathrm{Ca}^{2+}$ current, reduced the aging effect on slow after-hyperpolarization spikes to facilitate synaptic enhancement observed in the long-term potentiation [17, 43]. Finally, ryanodine, used to inhibit RyR and the amplification of $\mathrm{Ca}^{2+}$ entry via the L-type $\mathrm{Ca}^{2+}$ channels, had the same effect as observed with Nimoldipine [22]. Similar results were obtained in the heart: the age-associated decline of SERCA activity was related to the decrease of cardiac contraction induced by isoproterenol $[25,26]$. Finally, during development phases, the $\mathrm{Ca}^{2+}$ signaling pathways were also modified. In sheep cerebral arteries, the expression of CaV1.2 was decreased (from fetus to adult) coupled to a modification of norepinephrine contraction [5]. However, in cerebral arteries, aging could also alter the $\mathrm{Ca}^{2+}$ signaling and could have functional consequences on vascular reactivity. This aspect of vascular aging has not yet investigated.

If the decline in vascular reactivity due to aging has been repeatedly measured, all molecular mechanisms affected by aging are not well documented. Therefore, we have investigated the effects of aging on $\mathrm{Ca}^{2+}$ signaling, gene expression of $\mathrm{Ca}^{2+}$ signaling toolkit, and contraction. Our results suggest that in cerebral arteries, the decrease of contraction due to aging was due to the modification of amplitude and kinetic parameters of $\mathrm{Ca}^{2+}$ signals. These modifications could be explained by the modification of gene expression of the $\mathrm{Ca}^{2+}$ signaling toolkit observed in old mice.

\section{Methods}

Animals

The care and use of animals complied with European Community and French guiding principles. The principal investigator is authorized by French authorities to perform animal experiments (no. C33-01-029). The average weights were 24 $\pm 2 \mathrm{~g}(n=33)$ for young mice (2-3 months old) and $35 \pm 5 \mathrm{~g}(n=36)$ for old mice (20-22 months old). All C57Bl6/J were from Ets Janvier (Saint Berthevin, France). Mice were killed by cervical dissociation, brains were extracted of the skull, and the posterior (PCA) and middle (MCA) cerebral arteries were dissected.

Old animals (20-22 months) came into the laboratory at the age of 12 months. Approximately $20 \%$ died before reaching the age of 22 months, whilst the remaining $80 \%$ were in "good health," i.e., without visible characteristics of abating (no locomotor disorders, no difficulty with food or water intakes, and no lack of social interactions).

Quantitative real-time polymerase chain reaction after transcription

MasterPure ${ }^{\circledR}$ kit (Epicentre, Madison, WI) was used to isolate total RNA from cerebral arteries. RNA integrity and purity were verified by using RNA HighSens Analysis Kit (Experion, Bio-Rad, Marne-la-Coquette, France), and the concentration of RNA was measured with spectrophotometry (NanoDrop Technologies, Wilmington, DE). Reverse transcription (RT) reaction was carried out using the Sensiscript kit (Qiagen, Courtaboeuf, France). Obtained cDNA were amplified using the primers designed with primer3 software, and these were listed in the Supplementary Methods. The annealing temperature was determined with the gradient function of the CFX96 thermocycler (Bio-Rad), and the absence of primer dimerization was verified. The quantitative real-time polymerase chain reaction (qPCR) experiments were performed with the SYBR green PCR Master Mix (Bio-Rad) in the CFX96. The specificity of the amplification products was confirmed 
by melting curve analysis. All samples were analyzed in duplicates. PCR efficiency was calculated from the slope of the standard curve. Gene expression levels were calculated using the $2-\mathrm{ddCt}$ method normalized by reference genes. The optimal number and choice of reference genes have been experimentally determined by the GeNorm method [59] indicating the most stable reference genes in our experimental conditions (YWHAZ, RPL13A, and HPRT1). In the present experiments, we have used PCA and MCA from 15 young and old mice, and for the statistical analysis, we have restrained the samples to 12 young and old mice after the measurement of RNA quality and after GeNorm analysis.

Cytosolic $\mathrm{Ca}^{2+}$ measurements

After dissection, PCA and MCA were placed on glass slides coated with CellTak ${ }^{\mathrm{TM}}$ (BD-Biosciences, Le-Pont-de-Claix, France) and kept in M199 culture medium at $37{ }^{\circ} \mathrm{C}$ under an atmosphere supplemented with $5 \% \mathrm{CO}_{2}$ before being used in experiments. The PCA were loaded with $2.10^{-6} \mathrm{~mol} / \mathrm{L}$ Fluo8$\mathrm{AM} \mathrm{Ca}^{2+}$ probe for $20 \mathrm{~min}$ at $37^{\circ} \mathrm{C}$. Slides were then mounted in the experimental chamber, perfused with physiological solution [14], and placed on the confocal TCS SP5 system equipped with resonant scanner (Leica Microsystems, Nanterre, France), and images were acquired at 7 or $3 \mathrm{~Hz}$ in an image series mode. In experiments using cADPR and NAADP, arteries were permeabilized by using the previously described protocol [20]. Briefly, the physiological solution was replaced by a solution containing (in moles per liter) $1.410^{-1} \mathrm{KCl}, 2$ $10^{-2}$ Hepes, $510^{-4} \mathrm{MgCl} 2,10^{-4} \mathrm{ATP}$, and $10 \mu \mathrm{g} / \mathrm{mL}$ saponin. Experiments were performed $5 \mathrm{~min}$ after permeabilization, and, in order to limit the fluo8 leak, the $\mathrm{Ca}^{2+}$ response was recorded in the first $20 \mathrm{~min}$ after permeabilization. Fluorescence was analyzed with LAS-AF software (Leica Microsystems), and generated time course data were analyzed with a software developed by Michel Goillandeau (on request).

\section{UV photolysis}

Arteries were loaded with the membrane permeant derivative of caged InsP3: D-23-O-isopropylidene-6-O-(2nitro-4,5-demethoxy)benzyl-myo-Inositol 1,4,5-trisphosphate-Hexakis(propionoxymethyl)Ester (caged-145-InsP3; $2.10^{-6} \mathrm{~mol} / \mathrm{L}$ ) during 30 min before Fluo8-AM loading. Photolysis was produced by UV flash $\left(10^{-3} \mathrm{~s}\right)$ from DIPSI (Chatillon, France).

Artery contraction

PCA were cannulised at both ends in a video-monitored perfusion system (Living Systems Instrumentation, Burlington, VT) to measure the artery diameter continuously and were bathed in PSS (pH 7.4, $\mathrm{Po}_{2} 160 \mathrm{~mm} \mathrm{Hg}, \mathrm{Pco}_{2} 37 \mathrm{~mm} \mathrm{Hg}$ ). Pressure and flow were controlled. Contraction was expressed as the ratio between the passive diameter and the maximal artery diameter during agonist or pharmacological agent application [1].

Fluorescent pharmacology

Cerebral arteries were perfused during 20 min with $1.10^{-7}$ mol/L of ST-bodipy(-)-dihydropyridine (DHP) and imaged with the confocal TCS SP5 system using the 535-nm excitation wavelength during $\mathrm{Ca}^{2+}$ measurements. The emitted light was collected between 580 and $620 \mathrm{~nm}$. The fluorescence of each cell was measured and reported to evaluate the binding of DHP on L-type voltage-gated $\mathrm{Ca}^{2+}$ channels (VDCC). Nonspecific fixation of the ST-bodipy(-)-DHP was determined by simultaneous incubation with oxodipine $1.10^{-6} \mathrm{~mol} / \mathrm{L}$. All parameters of confocal microscope setup were kept constant for all experiments.

\section{Statistical analysis}

Statistical analysis was performed with Graphpad prism software (Graphpad software Inc, La Jolla, CA). Data are expressed as means $\pm \mathrm{SE}$; $n$ represents the number of tested cells or arteries. Significance between two different age groups (2-3 versus 20-22-month-old mice) or between control and treated arteries (in the absence versus presence of a pharmacological agent) was tested by means of Student's $t$ test or one way ANOVA completed with a Tukey post hoc test. $P$ values $<0.05$ were considered as significant and indicated by star symbols in the figures.

\section{Pharmacological agents}

Caffeine and ryanodine were purchased from MerckMillipore (Nottingham, UK), caged-145-InsP3 was from SiChem (Bremen, Germany), ST-bodipy(-)-DHP, and M199 medium were from Life Technologies (Saint-Aubin, France); NAADP was from BioLog (Bremen, Germany) and Fluo8-AM, thapsigargin, and secondary antibodies were from Interchim (Montluçon, France). All other chemical compounds were from Sigma-Aldrich (Saint-Louis, MO).

\section{Results}

Aging effects on RyR-dependent $\mathrm{Ca}^{2+}$ signals

The RyRs were directly activated by caffeine and cADPR and engaged in CICR to amplify $\mathrm{Ca}^{2+}$ entry. The comparison of $\mathrm{Ca}^{2+}$ responses induced by caffeine application $(0.01 \mathrm{~mol} / \mathrm{L})$ indicated that the amplitude of $\mathrm{Ca}^{2+}$ signals was reduced in old mice in PCA (Fig. 1a; $5.3 \pm 0.5$ ratio units in young mice; $n=$ 218 cells versus $2.9 \pm 0.6 ; n=237$ cells in old mice; $p=0.0001$ ). Likewise, the $\mathrm{Ca}^{2+}$ signal, evoked by depolarization due to the 
A
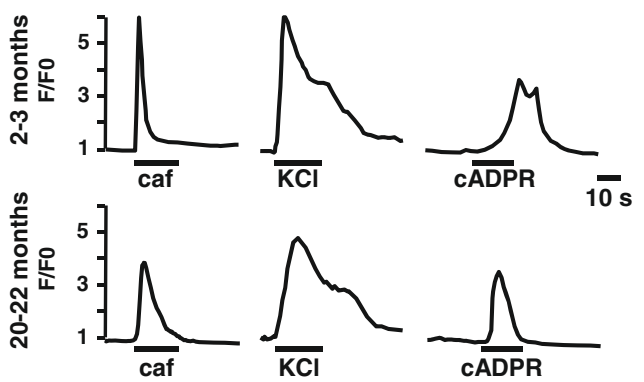

B
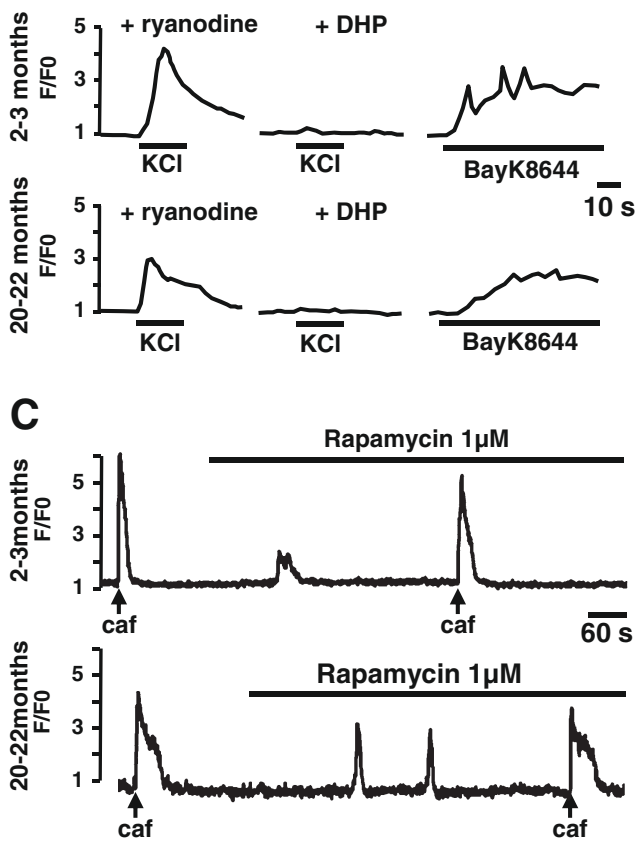

Fig. $1 \mathrm{Ca}^{2+}$ signals in PCA from young and old mice. a Typical $\mathrm{Ca}^{2+}$ responses evoked by caffeine (caf), $\mathrm{KCl}$, and cyclic ADP ribose $(c A D P R)$ in control condition. b Typical $\mathrm{Ca}^{2+}$ responses evoked by $\mathrm{KCl}$ in presence of ryanodine and DHP and typical BayK8644-evoked $\mathrm{Ca}^{2+}$ responses. c Typical $\mathrm{Ca}^{2+}$ responses evoked by caffeine in control condition and in presence of rapamycin

application of $0.14 \mathrm{~mol} / \mathrm{L} \mathrm{KCl}$ solution, was also decreased by aging in control conditions (Fig. 1a; $6.7 \pm 0.8$ ratio units in young mice; $n=178$ cells versus $4.6 \pm 0.4 ; n=187$ cells in old mice; $p<0.0001$ ) but also in the presence of $1.10^{-5} \mathrm{~mol} / \mathrm{L}$ ryanodine to inhibit RyR and CICR (Fig. 1b; $3.6 \pm 0.3$ ratio units in young mice; $n=218$ cells versus $2.0 \pm 0.4 ; n=237$ cells in old mice; $p<0.0001)$. The application of ST-bodipy(-)-DHP (inhibitor of L-type $\mathrm{Ca}^{2+}$ current, $1.10^{-6} \mathrm{~mol} / \mathrm{L}$ ) inhibited the $\mathrm{KCl}$-induced $\mathrm{Ca}^{2+}$ response (Fig. 1b), whereas the application of BayK8644 (used to activate L-type $\mathrm{Ca}^{2+}$ current, $1.10^{-8}$ $\mathrm{mol} / \mathrm{L}$ ), evoked a smaller $\mathrm{Ca}^{2+}$ signal in arteries from old mice (Fig. $2 \mathrm{~b} ; 2.1 \pm 0.3$ ratio units in young mice; $n=79$ cells versus $1.6 \pm 0.2 ; n=66$ cells in old mice; $p=0.004)$.

The interaction of RyR2 and calstabin-2 (FKBP12.6) was implicated in cADPR-induced $\mathrm{Ca}^{2+}$ response. In permeabilized PCA from old mice, the $\mathrm{Ca}^{2+}$ response evoked by cADPR $\left(1.10^{-6} \mathrm{~mol} / \mathrm{L}\right)$ was decreased in terms of area under the curve $(1.90 \pm 0.21$ ratio units/s, $n=23$ cells from young mice versus $1.10 \pm 0.18$ ratio units/s, $n=50$ cells from old mice; $p=0.02$; Fig. 1a). The application of $1.10^{-6} \mathrm{~mol} / \mathrm{L}$ rapamycin was used as a decoupling agent against FKBP12.6/RyR2 interaction. It was able to activate a $\mathrm{Ca}^{2+}$ signal but also affect the caffeineinduced $\mathrm{Ca}^{2+}$ response [20]. Rapamycin-evoked $\mathrm{Ca}^{2+}$ signals were increased in arteries from old mice (Fig. 1c); 6 min after rapamycin application, the amplitudes of the caffeine-induced $\mathrm{Ca}^{2+}$ response were decreased (Fig. 1c). These results suggested that aging reinforced the calstabin-2 regulation of $\mathrm{Ca}^{2+}$ signals.

Aging effects on InsP3-evoked $\mathrm{Ca}^{2+}$ responses

After loading of arteries with caged-145-InsP3 $\left(2.10^{-6} \mathrm{~mol} / \mathrm{L}\right)$ as described previously [14], we have performed its photolysis at several flash intensities to determine the apparent InsP3affinity. Flash intensity is proportional to the quantity of released InsP3. In PCA, the apparent InsP3 affinity was decreased in old mice, but the maximal $\mathrm{Ca}^{2+}$ responses were identical in both ages (Fig. 2).

\section{Aging effect on $\mathrm{Ca}^{2+}$ store refilling}

To investigate the $\mathrm{Ca}^{2+}$ store refilling, we have performed different protocols using successive caffeine applications or inhibition of SERCA by thapsigargin. In Fig. 3a, a second caffeine application followed the first one immediately after the return to the basal level (60-90 s); the amplitude of the second response was decreased in the arteries from young as well as in old mice, but the effect was more pronounced in aged mice ( -35 versus $-47 \%$ in young and old mice, respectively). In Fig. 3b, the delay between both caffeine applications was

\section{A}
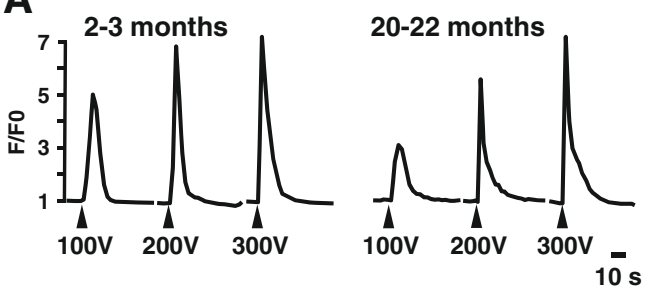

B

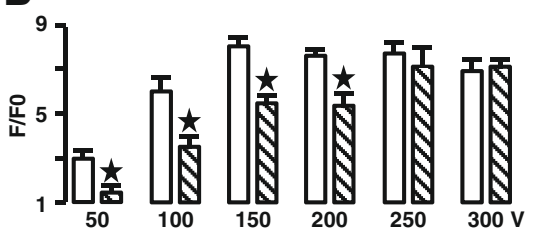

Fig. 2 InsP3-evoked $\mathrm{Ca}^{2+}$ release in PCA from young and old mice. a Typical $\mathrm{Ca}^{2+}$ responses evoked by photolysis of InsP3. b Mean of maximal amplitude of InsP3-activated $\mathrm{Ca}^{2+}$ responses in young (open bars) and old (hatched bars) mice. Sixty-five to 95 cells were tested for each condition. Data are expressed as mean \pm SEM; star indicates $p<0.05$ 
A

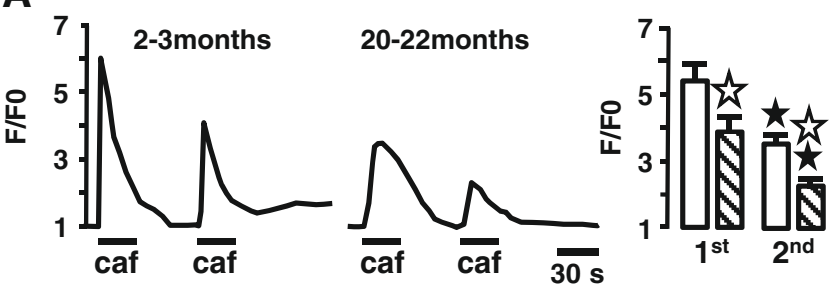

B

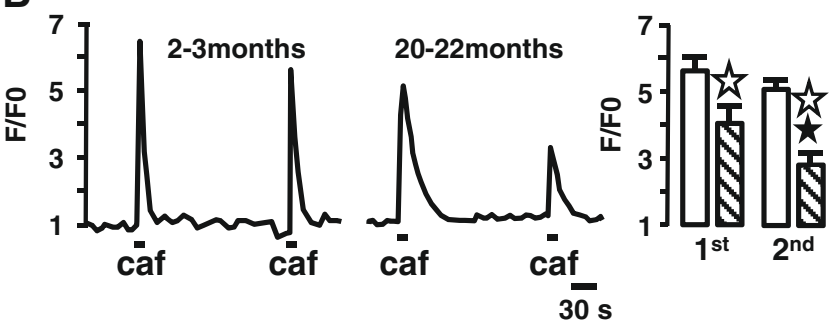

C

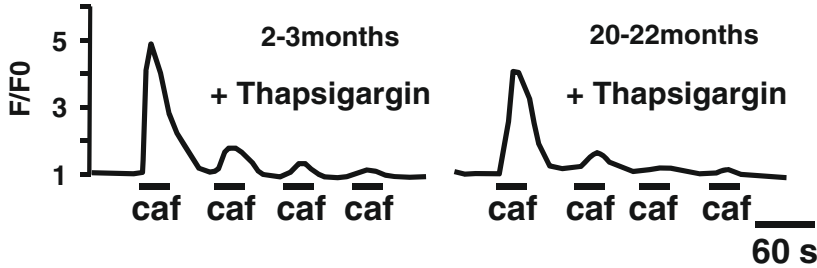

Fig. $3 \mathrm{Ca}^{2+}$ store refilling in PCA from young and old mice. a-b On the left, two consecutive caffeine-evoked $\mathrm{Ca}^{2+}$ responses separated by $60 \mathrm{~s}$ (a) or $210 \mathrm{~s}$; on the right, mean of maximal amplitude of evoked $\mathrm{Ca}^{2+}$ responses in young (open bars) and old (hatched bars) mice. Forty-six to 61 cells were tested for each condition. Data are expressed as mean \pm SEM; white star indicate $p<0.05$ between young and old mice; black star, $p<0.05$ between the first and the second responses. $\mathbf{c}$ Typical $\mathrm{Ca}^{2+}$ responses evoked by successive caffeine application in presence of thapsigargin

increased to $180-210 \mathrm{~s}$; the second caffeine-induced $\mathrm{Ca}^{2+}$ response was identical to the first one in young mice and decreased $(-35 \%)$ in arteries from old mice. These effects were significant (graph bars in Fig. 3a-b). Finally, successive caffeine applications were performed on arteries in the presence of thapsigargin $10^{-6} \mathrm{~mol} / \mathrm{L}$ (Fig. 3c). In this last case, the disappearance of the signal was more rapid and more pronounced in old mice. In all cases, the rates of decay of the caffeine-induced signals were significantly slowed in old mice (from $1.02 \pm 0.04$ ratio units (RU) $\mathrm{s}^{-1}(n=200)$ in young mice to $0.26 \pm 0.03(n=$ 91) RU s ${ }^{-1}$ in old mice). Taken together, these results indicate that the refilling of $\mathrm{Ca}^{2+}$ stores implicating SERCA and storeoperated channels was decreased in old mice.

Aging effects on expression of gene encoding $\mathrm{Ca}^{2+}$ signaling

As revealed by using antisense strategies or overexpression of genes encoding channels and pumps implicated in $\mathrm{Ca}^{2+}$ signaling, the decrease or the increase of gene expression were translated in terms of $\mathrm{Ca}^{2+}$ signals (data not shown) $[12,13,20]$. For this reason, we have investigated the expression levels of proteins implicated in recorded $\mathrm{Ca}^{2+}$ signals in cerebral arteries from young and old mice.

In PCA (Fig. 4a), aging induced the decrease of expressions of CaV1.2, RyR2, and the increase of FKBP12.6, as revealed by RT-qPCR. We have evaluated expression levels of proteins by using a fluorescent pharmacological agent and immunostainings because mouse cerebral arteries were too small for western blot analysis. As illustrated in Fig. 4b, the decreases of CaV1.2 labeling with ST-bodipy(-)-DHP $(p=0.004)$ and RyR2 immunostaining $(p=0.04)$, and the increase of FKBP12.6 immunostaining $(p=0.003)$ have been measured. These results could explain the modulation due to aging of $\mathrm{KCl}-$, caffeine-, and cADPR-evoked $\mathrm{Ca}^{2+}$ signals.

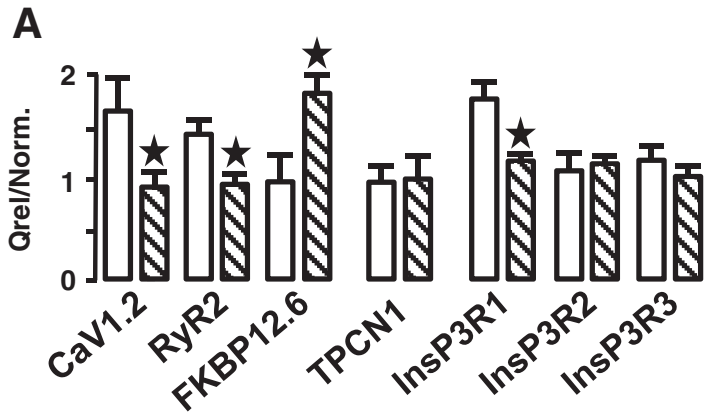

B
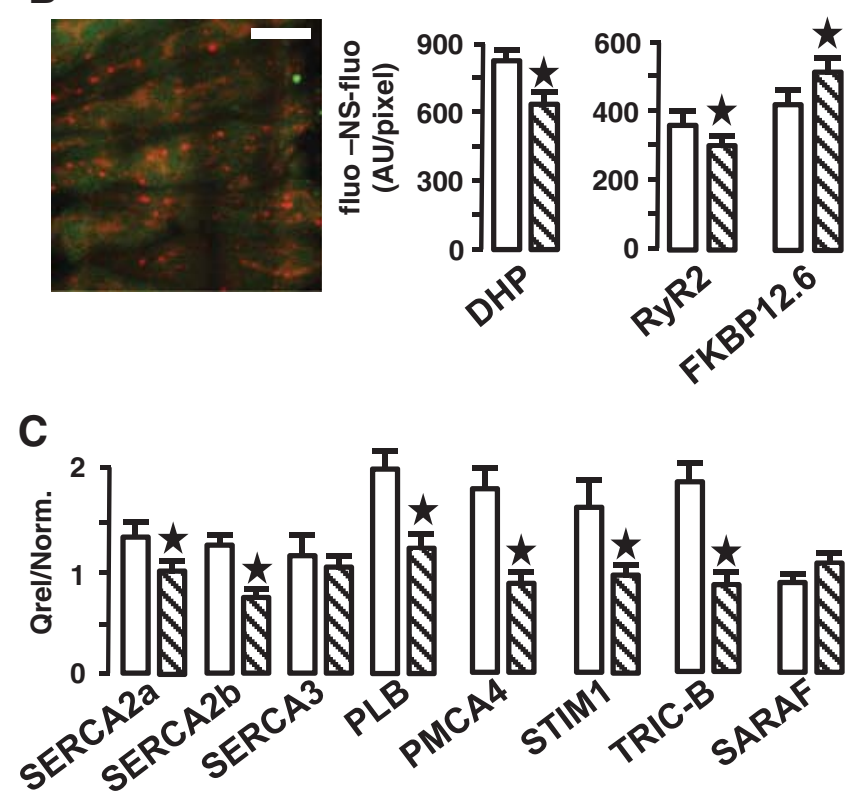

Fig. 4 Expression of channels and pumps. a-c Mean \pm SEM of gene expression level quantified after RT-qPCR in PCA from young (open bars, $n=12$ ) and old (hatched bars, $n=12$ ) mice. Star indicates $p<0.05$. b From left to right: typical labeling with ST-bodipy(-)-DHP labeling (red) and fluo-8 (green) in PCA. Mean of fluorescence emitted by ST-bodipy(-)DHP in PCA from young (open bars) and old (hatched bars) mice and means of fluorescence emitted by immunostaining of RyR2 and FKBP12.6 with specific antibodies. Data are expressed as mean \pm SEM; star, $p<0.05$ 
Aging effects on expression of gene encoding

$\mathrm{Ca}^{2+}$ store refilling

By RT-qPCR, the decreases of expression of SERCA2a, SERCA2b, PLB, STIM1, TRIC-B, and PMCA4 were measured in PCA (Fig. 4c) from old mice. The expression of SARAF, Orai1, PCMA1, STIM2, TRIC-A, TPCN1, and TPCN2 remained unchanged (Figs. 4a, c, and S2). The decreases of STIM1 and SERCA2 expressions were also verified by specific immunostaining ( $p=0.02$, Fig. S2). These results suggested that the aging-induced modifications of $\mathrm{Ca}^{2+}$ store refilling could also be explained by a modulation of gene expression.

Aging and contraction of cerebral arteries

Finally, these modifications of $\mathrm{Ca}^{2+}$ signals could have physiological significance as measured in contraction experiments. All signals were measured on the arteries from mice just after euthanasia; thus, we thought that vascular contraction would be the best indicator of physiological functioning. For technical reasons, only PCA contraction was measured. The contractions induced by caffeine $(0.01 \mathrm{~mol} / \mathrm{L})$ or $\mathrm{KCl}(0.14 \mathrm{~mol} / \mathrm{L})$ were both decreased (Fig. 5), whereas the phenylephrine $\left(10^{-5} \mathrm{~mol} / \mathrm{L}\right)$-induced maximal contraction was unchanged in PCA from old mice, suggesting that aging was unable to modify maximal signals induced by InsP3 as observed in $\mathrm{Ca}^{2+}$ experiments.

\section{Aging effects on MCA}

As illustrated in the Supplementary Data, the studies of $\mathrm{Ca}^{2+}$ signaling and gene expression were also performed in MCA from young and old mice. The $\mathrm{KCl}$-, caffeine-, and cADPRinduced $\mathrm{Ca}^{2+}$ responses as well as the $\mathrm{Ca}^{2+}$ refilling due to SERCA activation were affected by aging in MCA as observed in PCA (Fig. S3). In MCA, similar aging effects were observed on gene expressions encoding CaV1.2, RyR2, FKBP12.6, and proteins implicated in $\mathrm{Ca}^{2+}$ store refilling (Fig. S4).

However, a marked difference was found concerning the InsP3-dependent pathway. At low flash intensities, the InsP3-

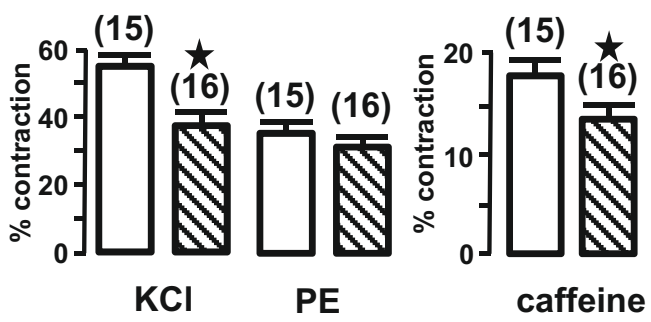

Fig. 5 Mean of $\mathrm{KCl}$-, phenylephrine-, and caffeine-induced contraction. Number of tested PCA was indicated in parenthesis in young (open bars) and old (hatched bars) mice. Data are expressed as mean \pm SEM; star indicates $p<0.05$ activated $\mathrm{Ca}^{2+}$ signal appeared similar in MCA from young and old mice, but at high flash intensity, the signal was significantly decreased in MCA from old mice (Fig. S5a-b). A bell-shaped concentration- $\mathrm{Ca}^{2+}$ response curve was observed for arteries from old mice (Fig. S5b). Obviously, we have controlled that the response obtained to $300-\mathrm{V}$ intensity flash was not due to a deleterious effect of flash on cell components: the caffeine-evoked $\mathrm{Ca}^{2+}$ responses obtained after the flash delivery were not different to those obtained in cells that were not exposed to the UV flash. Furthermore, the effect of aging on InsP3R expression was different in MCA. If only a decrease of InsP3R1 was observed in PCA, in MCA, a decrease of InsP3R3 and an increase of InsP3R2 were measured (Fig. S5c). The modification of the InsP3R expression pattern could be linked to the modification of InsP3 affinity and $\mathrm{Ca}^{2+}$ regulation that we observed.

Finally, aging regulated the NAADP-evoked $\mathrm{Ca}^{2+}$ responses in MCA but not in PCA. The application of $1.10^{-7} \mathrm{~mol} / \mathrm{L}$ of NAADP on permeabilized arteries induced similar $\mathrm{Ca}^{2+}$ signals in PCA from young and old mice $(2.0 \pm 0.19$ ratio units/s, $n=23$ cells from young mice versus $2.85 \pm 0.48$ ratio units/s, $n=21$ cells from old mice; $p=0.17$ ), but, in MCA, the NAADPevoked $\mathrm{Ca}^{2+}$ signals were significantly increased by aging (Fig. S6a-b). Recently, the TPCN channels were proposed as a target of NAADP. If the TPCN1 expression was not modulated by aging in PCA (Fig. 4a), in MCA, an increase of TPCN1 expression was revealed by RT-qPCR as well as by immunostaining (Fig. S6c-d). Thus, the increase of NAADPinduced $\mathrm{Ca}^{2+}$ response could be due to the increase of TPCN1.

\section{Discussion}

Effects of aging on the $\mathrm{Ca}^{2+}$ signaling have been well described in skeletal muscle [44] and neurons [10, 56] yet not exhaustively in VSMC [23]. Therefore, we focused our study on the channels and pumps involved in $\mathrm{Ca}^{2+}$ signaling implicated in the regulation of vascular reactivity. Our major result is that the $\mathrm{Ca}^{2+}$ signaling is affected by aging. If aging can affect vascular contraction, it is possible that the other $\mathrm{Ca}^{2+}$-dependent cellular mechanisms could be disrupted.

Aging affects vasoconstriction by decreasing the efficiency of second messengers to induce $\mathrm{Ca}^{2+}$ signals

In VSMC, hormones and neurotransmitters converge on calcium signals via different transduction pathways. The vasoconstrictions induced by alpha-adrenergic, angiotensin-II, and endothelin-1 stimulations implicate InsP3, CaV1.2, and NAADP [32, 41, 54], cADPR and CaV1.2 [18, 40], and InsP3 and NAADP $[6,33]$, respectively. In elderly humans, the vasoconstriction induced by alpha-adrenergic stimulation was decreased [52], but the mechanism was not described. 
Assuming that the affinity of agonists and transduction pathways could be modified, ultimately the $\mathrm{Ca}^{2+}$ signal relies on second messenger activation.

The decrease of fluorescent DHP binding found in our study could reflect a decrease in the expression of L-type $\mathrm{Ca}^{2+}$ channels rather than a post-transductional change that would result more in a change in ligand affinity [28]. Thus, the decrease of depolarisation-induced $\mathrm{Ca}^{2+}$ signal and contraction could be attributed to the decrease of CaV1.2 expression. The calstabin-2/RyR2 interaction is regulated by cADPR to control CICR mechanism and $\mathrm{Ca}^{2+}$ oscillations induced by neurotransmitters [20]. As expected, the overexpression of calstabin-2 in association with the decrease of RyR2 affected the cADPR-evoked $\mathrm{Ca}^{2+}$ signal.

In the present study, aging causes a decrease of InsP3R1 in benefit of InsP3R3 in PCA and a slight increase of InsP3R2 expression in MCA. The InsP3R subtypes have different sensitivities to InsP3 and are modulated by $\mathrm{Ca}^{2+}$. The InsP3R2 has the highest sensitivity to InsP3 and was regulated by $\mathrm{Ca}^{2+}$ in a bell-shaped concentration-dependent manner, whereas the InsP3R3 has the lowest InsP3 sensitivity and was very weakly modulated by $\mathrm{Ca}^{2+}$ in comparison with both other subtypes $[36,42,53]$. As we have previously shown in smooth muscle $[21,39]$, the increase of InsP3R3 proportion could explain the decrease of the InsP3 affinity to induce $\mathrm{Ca}^{2+}$ signals without change in the maximal $\mathrm{Ca}^{2+}$ response. On the other hand, in $\mathrm{MCA}$, the increase of InsP3R2 proportion induces a higher InsP3 affinity and leads to inhibition by $\mathrm{Ca}^{2+}$ of InsP3 receptors [58], inducing a large modification of the maximal response as described in engineered cells expressing different combinations of InsP3R subtypes [53]. The apparent modification in the downstroke velocity could probably be due to the decrease of extrusion mechanisms. Finally, NAADP evoked $\mathrm{Ca}^{2+}$ signals by activation of RyR and TPCN channels [27, 67] directly or after interaction with a NAADP-binding cytosolic protein [60]. TPCN1 is required in NAADP-induced $\mathrm{Ca}^{2+}$ signal [7] and as observed in MCA, the increase of TPCN1 is sufficient to explain the increase of NAADP-induced $\mathrm{Ca}^{2+}$ response. Taken together, our results indicate that the $\mathrm{Ca}^{2+}$-induced $\mathrm{Ca}^{2+}$ release by agonist depends on the effect of second messengers on their receptor channels to induce contraction.

\section{Aging attenuates amplification of $\mathrm{Ca}^{2+}$ signals by CICR}

Another crucial step in the $\mathrm{Ca}^{2+}$ signals is the amplification due to the CICR. It is well accepted that RyR2 has a predominant function in the mechanism of CICR after depolarization of VSMC [11, 13]. Our results confirm and precise those obtained on mesenteric arteries from 30-month-old C57Bl6/j mice, describing a decrease of caffeine-induced $\mathrm{Ca}^{2+}$ signaling [16]. Moreover, the decrease of RyR expression could also explain the alteration of myogenic tone observed in cerebral arteries from old mice [24]. Indeed, RyR are responsible for
$\mathrm{Ca}^{2+}$ sparks and $\mathrm{Ca}^{2+}$-activated $\mathrm{K}^{+}$channels, yet they were also implicated in the regulation of myogenic tone [15].

These results also suggest that the level of RyR2 expression could be a regulator of the VSMC reactivity in aged subjects as well as in physiopathological conditions such as in dystrophic mdx mice [38]. Moreover, we have demonstrated, by RT-qPCR as well as by immunostaining, an increase of calstabin-2 gene expression that could increase the inhibition of RyR2. In cardiomyocytes, the overexpression of calstabin-2 was responsible for a decrease of RyRdependent $\mathrm{Ca}^{2+}$ leak [48]. In fact, calstabin-2 stabilizes RyR2 in a resting state via molecular interactions, which results in inhibiting the release of SR-stored $\mathrm{Ca}^{2+}$ [30].

Aging reduces the velocity of $\mathrm{Ca}^{2+}$ store refilling

Our results have shown that $\mathrm{Ca}^{2+}$ store refilling was decelerated with aging. Both ATPase pumps (SERCA and PMCA) are implicated in the return to basal level of the $\mathrm{Ca}^{2+}$ signals. It has been demonstrated in aging neurons [35] and in CHO cells [8] that a change of 20-25\% in their expression level can significantly modify $\mathrm{Ca}^{2+}$ signals. Our consistent results thus suggest that the decrease of the expression of PMCA4 and SERCA2 could be responsible for the aging effect on the return to basal $\mathrm{Ca}^{2+}$ level.

The refilling of the $\mathrm{Ca}^{2+}$ store also depends on storeoperated $\mathrm{Ca}^{2+}$ entry (SOCE) that cannot be easily measured in native VSMC. As illustrated in Fig. S1, the mechanism of SOCE includes a stoichiometric interaction of Orai or TRPC in the plasma membrane with STIM in the SR [50]. The decrease of STIM expression observed in our study suggests that SOCE. Recently, two new regulators of store refilling have been identified and located in the sarcoplasmic membrane: SARAF [45] and the TRIC-A and -B channels [62, 63, 65]. The decrease of SARAF expression induced the increase of resting $\left[\mathrm{Ca}^{2+}\right] \mathrm{i}$ associated with the decrease of the reticulum $\mathrm{Ca}^{2+}$ loading [45], whereas the TRIC-B knockout induced a reticulum $\mathrm{Ca}^{2+}$ overloading and decrease of resting $\left[\mathrm{Ca}^{2+}\right] \mathrm{i}$ [62]. These data therefore suggested that SARAF and TRIC-B have antagonist functions. Likewise, our data suggest that TRIC-B and SARAF expressions were modulated in opposite way by aging to neutralize a putative effect on resting $\left[\mathrm{Ca}^{2+}\right]$ i. However, we did not measure a significant modification in resting $\left[\mathrm{Ca}^{2+}\right] \mathrm{i}$ by using a combination of $\mathrm{Ca}^{2+}$ probes (not shown).

\section{Conclusion and perspectives}

Our results strongly suggest an adaptation to time as our study has examined the effects of aging in otherwise healthy animals having access to a balanced diet. The adaptation of the $\mathrm{Ca}^{2+}$ signaling toolkit induces a modulation of vascular reactivity (decrease of CICR) but could also affect lysosomal/endosomal 
functions and cell regeneration implicated in aging-dependent vascular physiology and pathologies. Aging can affect directly or indirectly many molecular assemblies implicated in vascular reactivity such as $\mathrm{Ca}^{2+}$ signaling (this study), the contractile apparatus [49], probably its $\mathrm{Ca}^{2+}$ sensitivity via the Rho/Rhokinase pathway, decrease of voltage- and $\mathrm{Ca}^{2+}$-dependent potassium channels [34] (Georgeon-Chartier, Morel, personal preliminary data), and basal NO level in endothelial cells [51]. Our results could help understand the effects of aging on cardiovascular pathological risks. As we observed in mice, a decrease of expression of CaV1.2 in atherosclerotic carotids was described in elderly men [57]. The overexpression of calstabin-2 was also implicated in cell hypertrophy and apoptosis [66]. Finally, the increase of TPCN1 could increase the arteriosclerosis risk through the implication of NAADP in autophagy [47] and inflammation [64], two components of arteriosclerosis.

Therefore, our results could indicate that the regulation of gene expression of proteins implicated in $\mathrm{Ca}^{2+}$ signaling is an adaptation to aging as well as a risk factor for vascular diseases linked to old age.

Acknowledgments CGC has performed RT-qPCR experiments, fluorescent pharmacology, and $\mathrm{Ca}^{2+}$ measurements; $\mathrm{CM}$ has performed contraction experiments, supervised experiments, and interpretation of results; and JLM and AP wrote the manuscript. We thank A. Joutel for a helpful discussion; D. Berracochea who gave us old mice to initiate the project; A. Donadieu and N. Biendon for technical assistance; and M. Goillandeau for software development (IMN software facilities). The study was supported by grants from the Centre National des Etudes Spatiales, from CNRS (longevity and aging specific action), and Agence Nationale pour la Recherche (AdapHyG no. ANR-09BLAN-0148) and Region Aquitaine (CGC doctoral fellowship and confocal microscope).

Conflict of interest There is no conflict of interest with funding providers.

\section{References}

1. Belin de Chantemele EJ, Retailleau K, Pinaud F, Vessieres E, Bocquet A, Guihot AL, Lemaire B, Domenga V, Baufreton C, Loufrani L, Joutel A, Henrion D (2008) Notch3 is a major regulator of vascular tone in cerebral and tail resistance arteries. Arterioscler Thromb Vasc Biol 28(12):2216-2224. doi:10.1161/ ATVBAHA.108.171751

2. Berridge MJ (2003) Cardiac calcium signalling. Biochem Soc Trans 31(Pt 5):930-933. doi:10.1042/

3. Berridge MJ (2008) Smooth muscle cell calcium activation mechanisms. J Physiol 586(Pt 21):5047-5061. doi:10.1113/ jphysiol.2008.160440

4. Berridge MJ, Lipp P, Bootman MD (2000) The versatility and universality of calcium signalling. Nat Rev Mol Cell Biol 1 (1):11-21. doi:10.1038/35036035

5. Blood AB, Zhao Y, Long W, Zhang L, Longo LD (2002) L-type Ca2 + channels in fetal and adult ovine cerebral arteries. Am J Physiol Regul Integr Comp Physiol 282(1):R131-R138. doi:10.1152/ ajpregu.00318.2001
6. Boittin FX, Galione A, Evans AM (2002) Nicotinic acid adenine dinucleotide phosphate mediates $\mathrm{Ca} 2+$ signals and contraction in arterial smooth muscle via a two-pool mechanism. Circ Res 91 (12):1168-1175

7. Brailoiu E, Churamani D, Cai X, Schrlau MG, Brailoiu GC, Gao X, Hooper R, Boulware MJ, Dun NJ, Marchant JS, Patel S (2009) Essential requirement for two-pore channel 1 in NAADP-mediated calcium signaling. J Cell Biol 186(2):201-209. doi:10.1083/ jcb.200904073

8. Brini M, Bano D, Manni S, Rizzuto R, Carafoli E (2000) Effects of PMCA and SERCA pump overexpression on the kinetics of cell Ca2+ signalling. EMBO J 19(18):4926-4935

9. Calcraft PJ, Ruas M, Pan Z, Cheng X, Arredouani A, Hao X, Tang J, Rietdorf K, Teboul L, Chuang K-T, Lin P, Xiao R, Wang C, Zhu Y, Lin Y, Wyatt CN, Parrington J, Ma J, Evans AM, Galione A, Zhu MX (2009) NAADP mobilizes calcium from acidic organelles through two-pore channels. Nature 459 (7246):596-600. doi:http:// www.nature.com/nature/journal/v459/n7246/suppinfo/nature08030 S1.html

10. Camandola S, Mattson MP (2011) Aberrant subcellular neuronal calcium regulation in aging and Alzheimer's disease. Biochim Biophys Acta (BBA) - Mol Cell Res 1813(5):965-973. doi:10.1016/j.bbamcr.2010.10.005

11. Coussin F, Macrez N, Morel J-L, Mironneau J (2000) Requirement of ryanodine receptor subtypes 1 and 2 for $\mathrm{Ca} 2+$-induced $\mathrm{Ca} 2+$ release in vascular myocytes. J Biol Chem 275(13):9596-9603. doi:10.1074/jbc.275.13.9596

12. Dabertrand F, Fritz N, Mironneau J, Macrez N, Morel JL (2007) Role of RYR3 splice variants in calcium signaling in mouse nonpregnant and pregnant myometrium. Am J Physiol Cell Physiol 293(3):C848-C854. doi:10.1152/ajpcell.00069.2007

13. Dabertrand F, Mironneau J, Macrez N, Morel JL (2008) Full length ryanodine receptor subtype 3 encodes spontaneous calcium oscillations in native duodenal smooth muscle cells. Cell Calcium 44 (2):180-189. doi:10.1016/j.ceca.2007.11.009

14. Dabertrand F, Porte Y, Macrez N, Morel J-L (2012) Spaceflight regulates ryanodine receptor subtype 1 in portal vein myocytes in the opposite way of hypertension. J Appl Physiol 112(3):471-480. doi:10.1152/japplphysiol.00733.2011

15. Davis MJ, Hill MA (1999) Signaling mechanisms underlying the vascular myogenic response. Physiol Rev 79(2):387-423

16. del Corsso C, Ostrovskaya O, McAllister CE, Murray K, Hatton WJ, Gurney AM, Spencer NJ, Wilson SM (2006) Effects of aging on Ca2 + signaling in murine mesenteric arterial smooth muscle cells. Mech Ageing Dev 127(4):315-323. doi:10.1016/j.mad.2005.12.001

17. Disterhoft JF, Thompson LT, Moyer JR Jr, Mogul DJ (1996) Calcium-dependent afterhyperpolarization and learning in young and aging hippocampus. Life Sci 59(5-6):413-420

18. Fellner SK, Arendshorst WJ (2005) Angiotensin II Ca2+ signaling in rat afferent arterioles: stimulation of cyclic ADP ribose and IP3 pathways. Am J Physiol Ren Physiol 288(4):F785-F791. doi:10.1152/ ajprenal.00372.2004

19. Feske S, Gwack Y, Prakriya M, Srikanth S, Puppel S-H, Tanasa B, Hogan PG, Lewis RS, Daly M, Rao A (2006) A mutation in Orai1 causes immune deficiency by abrogating CRAC channel function. Nature 441 (7090):179-185. doi:http://www.nature.com/nature/ journal/v441/n7090/suppinfo/nature04702_S1.html

20. Fritz N, Macrez N, Mironneau J, Jeyakumar LH, Fleischer S, Morel JL (2005) Ryanodine receptor subtype 2 encodes Ca2+ oscillations activated by acetylcholine via the M2 muscarinic receptor/cADP-ribose signalling pathway in duodenum myocytes. J Cell Sci 118(Pt 10):2261-2270. doi:10.1242/jcs.02344

21. Fritz N, Mironneau J, Macrez N, Morel JL (2008) Acetylcholineinduced $\mathrm{Ca} 2+$ oscillations are modulated by a $\mathrm{Ca} 2+$ regulation of InsP3R2 in rat portal vein myocytes. Pflugers Arch Eur J Physiol 456(2):277-283. doi:10.1007/s00424-007-0379-z 
22. Gant JC, Sama MM, Landfield PW, Thibault O (2006) Early and simultaneous emergence of multiple hippocampal biomarkers of aging is mediated by $\mathrm{Ca} 2+-$-Induced $\mathrm{Ca} 2+$ release. J Neurosci 26 (13):3482-3490. doi:10.1523/jneurosci.4171-05.2006

23. Goyal R, Angermann JE, Ostrovskaya O, Buchholz JN, Smith GD, Wilson SM (2009) Enhanced capacitative calcium entry and sarcoplasmic-reticulum calcium storage capacity with advanced age in murine mesenteric arterial smooth muscle cells. Exp Gerontol 44(3):201-207. doi:10.1016/j.exger.2008.10.007

24. Gros R, Van Wert R, You X, Thorin E, Husain M (2002) Effects of age, gender, and blood pressure on myogenic responses of mesenteric arteries from C57BL/6 mice. Am J Physiol Heart Circ Physiol 282(1):H380-H388

25. Jiang MT, Moffat MP, Narayanan N (1993) Age-related alterations in the phosphorylation of sarcoplasmic reticulum and myofibrillar proteins and diminished contractile response to isoproterenol in intact rat ventricle. Circ Res 72(1):102-111

26. Jiang MT, Narayanan N (1990) Effects of aging on phospholamban phosphorylation and calcium transport in rat cardiac sarcoplasmic reticulum. Mech Ageing Dev 54(1):87-101

27. Kinnear NP, Boittin F-X, Thomas JM, Galione A, Evans AM (2004) Lysosome-sarcoplasmic reticulum junctions. J Biol Chem 279(52):54319-54326. doi:10.1074/jbc.M406132200

28. Knaus HG, Moshammer T, Friedrich K, Kang HC, Haugland RP, Glossman H (1992) In vivo labeling of L-type Ca2+ channels by fluorescent dihydropyridines: evidence for a functional, extracellular heparin-binding site. Proc Natl Acad Sci U S A 89(8):3586-3590

29. Lee CK, Allison DB, Brand J, Weindruch R, Prolla TA (2002) Transcriptional profiles associated with aging and middle age-onset caloric restriction in mouse hearts. Proc Natl Acad Sci U S A 99 (23):14988-14993. doi:10.1073/pnas.232308999

30. Lehnart SE, Huang F, Marx SO, Marks AR (2003) Immunophilins and coupled gating of ryanodine receptors. Curr Top Med Chem 3 (12):1383-1391

31. Luik RM, Wang B, Prakriya M, Wu MM, Lewis RS (2008) Oligomerization of STIM1 couples ER calcium depletion to CRAC channel activation. Nature 454 (7203):538-542. doi:http:// www.nature.com/nature/journal/v454/n7203/suppinfo/nature07065 S1.html

32. Macrez-Lepretre N, Kalkbrenner F, Schultz G, Mironneau J (1997) Distinct functions of $\mathrm{Gq}$ and G11 proteins in coupling alpha1adrenoreceptors to $\mathrm{Ca} 2+$ release and $\mathrm{Ca} 2+$ entry in rat portal vein myocytes. J Biol Chem 272(8):5261-5268

33. Macrez N, Morel JL, Mironneau J (1999) Specific galpha11beta3gamma5 protein involvement in endothelin receptor-induced phosphatidylinositol hydrolysis and $\mathrm{Ca} 2+$ release in rat portal vein myocytes. Mol Pharmacol 55(4):684-692

34. Marijic J, Li Q, Song M, Nishimaru K, Stefani E, Toro L (2001) Decreased expression of voltage- and $\mathrm{Ca} 2+$-activated $\mathrm{K}+$ channels in coronary smooth muscle during aging. Circ Res 88(2):210-216. doi:10.1161/01.res.88.2.210

35. Michaelis ML, Bigelow DJ, Schoneich C, Williams TD, Ramonda L, Yin D, Huhmer AF, Yao Y, Gao J, Squier TC (1996) Decreased plasma membrane calcium transport activity in aging brain. Life Sci 59(5-6):405-412

36. Miyakawa T, Maeda A, Yamazawa T, Hirose K, Kurosaki T, Iino M (1999) Encoding of Ca2+ signals by differential expression of IP3 receptor subtypes. EMBO J 18(5):1303-1308. doi:10.1093/ emboj/18.5.1303

37. Moore A, Mangoni AA, Lyons D, Jackson SH (2003) The cardiovascular system. Br J Clin Pharmacol 56(3):254-260

38. Morel JL, Dabertrand F, Fritz N, Henaff M, Mironneau J, Macrez $\mathrm{N}$ (2009) The decrease of expression of ryanodine receptor subtype 2 is reversed by gentamycin sulphate in vascular myocytes from mdx mice. J Cell Mol Med 13(9B):3122-3130. doi:10.1111/ j.1582-4934.2009.00718.x
39. Morel JL, Fritz N, Lavie JL, Mironneau J (2003) Crucial role of type 2 inositol 1,4,5-trisphosphate receptors for acetylcholine-induced $\mathrm{Ca} 2+$ oscillations in vascular myocytes. Arterioscler Thromb Vasc Biol 23(9):1567-1575. doi:10.1161/01.ATV.0000089013.82552.5D

40. Morel JL, Macrez-Lepretre N, Mironneau J (1996) Angiotensin IIactivated $\mathrm{Ca} 2+$ entry-induced release of $\mathrm{Ca} 2+$ from intracellular stores in rat portal vein myocytes. Br J Pharmacol 118(1):73-78

41. Nelson MT, Standen NB, Brayden JE, Worley JF 3rd (1988) Noradrenaline contracts arteries by activating voltage-dependent calcium channels. Nature 336(6197):382-385. doi:10.1038/336382a0

42. Newton CL, Mignery GA, Sudhof TC (1994) Co-expression in vertebrate tissues and cell lines of multiple inositol 1,4,5-trisphosphate (InsP3) receptors with distinct affinities for InsP3. J Biol Chem 269(46):28613-28619

43. Norris CM, Halpain S, Foster TC (1998) Reversal of age-related alterations in synaptic plasticity by blockade of L-type $\mathrm{Ca} 2+$ channels. J Neurosci Off J Soc Neurosci 18(9):3171-3179

44. O’Connell K, Gannon J, Doran P, Ohlendieck K (2008) Reduced expression of sarcalumenin and related $\mathrm{Ca} 2+$-regulatory proteins in aged rat skeletal muscle. Exp Gerontol 43(10):958-961. doi:10.1016/j.exger.2008.07.006

45. Palty R, Raveh A, Kaminsky I, Meller R, Reuveny E (2012) SARAF Inactivates the store operated calcium entry machinery to prevent excess calcium refilling. Cell 149(2):425-438. doi:10.1016/j.cell.2012.01.055

46. Park S-K, Kim K, Page GP, Allison DB, Weindruch R, Prolla TA (2009) Gene expression profiling of aging in multiple mouse strains: identification of aging biomarkers and impact of dietary antioxidants. Aging Cell 8(4):484 495. doi:10.1111/j.1474-9726.2009.00496.x

47. Pereira GJS, Hirata H, Fimia GM, do Carmo LG, Bincoletto C, Han SW, Stilhano RS, Ureshino RP, Bloor-Young D, Churchill G, Piacentini M, Patel S, Smaili SS (2011) Nicotinic acid adenine dinucleotide phosphate (NAADP) regulates autophagy in cultured astrocytes. J Biol Chem 286(32):27875-27881. doi:10.1074/ jbc.C110.216580

48. Prestle J, Janssen PML, Janssen AP, Zeitz O, Lehnart SE, Bruce L, Smith GL, Hasenfuss G (2001) Overexpression of FK506-binding protein FKBP12.6 in cardiomyocytes reduces ryanodine receptorediated $\mathrm{Ca} 2+$ leak from the sarcoplasmic reticulum and increases contractility. Circ Res 88(2):188-194. doi:10.1161/01.res.88.2.188

49. Shehadeh LA, Webster KA, Hare JM, Vazquez-Padron RI (2011) Dynamic regulation of vascular myosin light chain (MYL9) with injury and aging. PLoS One 6(10):e25855. doi:10.1371/journal.pone.0025855

50. Shen WW, Frieden M, Demaurex N (2011) Remodelling of the endoplasmic reticulum during store-operated calcium entry. Biol Cell 103(8):365-380. doi:10.1042/BC20100152

51. Shipley RD, Muller-Delp JM (2005) Aging decreases vasoconstrictor responses of coronary resistance arterioles through endothelium-dependent mechanisms. Cardiovasc Res 66(2):374383. doi:10.1016/j.cardiores.2004.11.005

52. Smith EG, Voyles WF, Kirby BS, Markwald RR, Dinenno FA (2007) Ageing and leg postjunctional $\alpha$-adrenergic vasoconstrictor responsiveness in healthy men. J Physiol 582(1):63-71. doi:10.1113/ jphysiol.2007.130591

53. Sugawara H, Kurosaki M, Takata M, Kurosaki T (1997) Genetic evidence for involvement of type 1, type 2 and type 3 inositol 1,4,5trisphosphate receptors in signal transduction through the B-cell antigen receptor. EMBO J 16(11):3078-3088. doi:10.1093/emboj/ 16.11.3078

54. Thai TL, Churchill GC, Arendshorst WJ (2009) NAADP receptors mediate calcium signaling stimulated by endothelin-1 and norepinephrine in renal afferent arterioles. Am J Physiol Ren Physiol 297(2): F510-F516. doi:10.1152/ajprenal.00116.2009

55. Thibault O, Hadley R, Landfield PW (2001) Elevated postsynaptic $[\mathrm{Ca} 2+] \mathrm{i}$ and L-type calcium channel activity in aged hippocampal 
neurons: relationship to impaired synaptic plasticity. J Neurosci Off J Soc Neurosci 21(24):9744-9756

56. Thibault O, Landfield PW (1996) Increase in single L-type calcium channels in hippocampal neurons during aging. Science 272 (5264):1017-1020

57. Tiwari S, Zhang Y, Heller J, Abernethy DR, Soldatov NM (2006) Atherosclerosis-related molecular alteration of the human CaV1.2 calcium channel $\alpha 1 \mathrm{C}$ subunit. Proc Natl Acad Sci 103(45):1702417029. doi:10.1073/pnas.0606539103

58. Uhlén P, Fritz N (2010) Biochemistry of calcium oscillations. Biochem Biophys Res Commun 396(1):28-32. doi:10.1016/ j.bbrc.2010.02.117

59. Vandesompele J, De Preter K, Pattyn F, Poppe B, Van Roy N, De Paepe A, Speleman F (2002) Accurate normalization of real-time quantitative RT-PCR data by geometric averaging of multiple internal control genes. Genome Biol 3(7):RESEARCH0034

60. Walseth TF, Lin-Moshier Y, Jain P, Ruas M, Parrington J, Galione A, Marchant JS, Slama JT (2012) Photoaffinity labeling of high affinity nicotinic acid adenine dinucleotide phosphate (NAADP)binding proteins in sea urchin egg. J Biol Chem 287(4):23082315. doi:10.1074/jbc.M111.306563

61. Weindruch R, Kayo T, Lee CK, Prolla TA (2002) Gene expression profiling of aging using DNA microarrays. Mech Ageing Dev 123 (2-3):177-193

62. Yamazaki D, Komazaki S, Nakanishi H, Mishima A, Nishi M, Yazawa M, Yamazaki T, Taguchi R, Takeshima H (2009) Essential role of the TRIC-B channel in $\mathrm{Ca} 2+$ handling of alveolar epithelial cells and in perinatal lung maturation. Development 136 (14):2355-2361. doi:10.1242/dev.036798

63. Yamazaki D, Tabara Y, Kita S, Hanada H, Komazaki S, Naitou D, Mishima A, Nishi M, Yamamura H, Yamamoto S, Kakizawa S, Miyachi H, Yamamoto S, Miyata T, Kawano Y, Kamide K, Ogihara T, Hata A, Umemura S, Soma M, Takahashi N, Imaizumi Y, Miki T, Iwamoto T, Takeshima H (2011) TRIC-A channels in vascular smooth muscle contribute to blood pressure maintenance. Cell Metab 14(2):231-241. doi:10.1016/j.cmet.2011.05.011

64. Zhang F, Xia M, Li P-L (2010) Lysosome-dependent Ca2+ release response to Fas activation in coronary arterial myocytes through NAADP: evidence from CD38 gene knockouts. Am J Physiol Cell Physiol 298(5):C1209-C1216. doi:10.1152/ajpcell.00533.2009

65. Zhao X, Yamazaki D, Park KH, Komazaki S, Tjondrokoesoemo A, Nishi M, Lin P, Hirata Y, Brotto M, Takeshima H, Ma J (2010) Ca2+ Overload and sarcoplasmic reticulum instability in TRIC-A null skeletal muscle. J Biol Chem 285(48):37370-37376. doi:10.1074/ jbc.M110.170084

66. Zhong J, Chen J, Cao T, Wang L, Zhang W, Liu D, Zhu Z (2009) Adenovirus-mediated FKBP12.6 overexpression induces hypertrophy and apoptosis in cultured neonatal cardiomyocytes. Clin Exp Pharmacol Physiol 36(2):135-140. doi:10.1111/j.14401681.2008.05030.x

67. Zhu MX, Ma J, Parrington J, Calcraft PJ, Galione A, Evans AM (2010) Calcium signaling via two-pore channels: local or global, that is the question. Am J Physiol Cell Physiol 298(3):C430-C441. doi:10.1152/ajpcell.00475.2009 